\title{
Apresentação: \\ A atualidade do conceito \\ de gerações na \\ pesquisa sociológica
}

Alda Britto da Motta

Wivian Weller ${ }^{1}$

1. Organizadoras do dossiê.

[C] om a virada do século, o conceito de gerações recupera o seu espaço nas análises sociológicas que indicam não somente as diferenças de classe, mas ainda as desigualdades de gênero, étnicoraciais, culturais e geracionais. Vivemos ainda um momento em que a reconstrução das trajetórias sociais das gerações anteriores torna-se imprescindível para a análise e compreensão das ações coletivas empreendidas pelas novas gerações, bem como dos desafios que as mesmas enfrentam.

Dentre os muitos legados e trajetórias sociais de nossos antepassados que carecem de novas leituras a partir do tempo existencial dos indivíduos e do tempo social, coletivo e histórico, poderíamos citar o pensamento político da geração 1968 e o que dele persiste nos dias atuais, as trajetórias sociais dos indivíduos que ultrapassaram os anos mais avançados no tempo de vida, as mudanças e permanências nos modelos familiares ao longo das últimas gerações e, por último, mas não menos importante, as percepções sobre a juventude e sobre ser jovem por distintas gerações.

O termo gerações tornou-se popular na denominação de manifestações culturais ou políticas (geração hip-hop; geração caras pintadas) ou de desenvolvimentos tecnológicos (geração $\mathrm{Y}$; geração Net), atribuídos sobretudo pelos meios contemporâneos de comunicação. No entanto, muitos estudos são desenvolvidos a partir de uma perspectiva que contempla uma determinada geração de forma isolada, como uma espécie de unidade desconectada de outras gerações e de seu tempo histórico. Percebe-se uma certa inflação do conceito seguida de uma destituição de seu sentido 
teórico na medida em que o termo geração passou a ser utilizado, muitas vezes, como sinônimo para denominar uma faixa etária ou um grupo com características específicas (cf. Corsten, 2010: 134).

Os cientistas sociais procuram superar esse fato agindo em duas direções fundamentais nos estudos e pesquisas sobre gerações. Primeiro, pela tradição antropológica, referindo-se principalmente a várias formas de grupos e categorias de idade, em um sentido genealógico ou de filiação, porém mantendo um sentido ou uma função classificatória que inclui tanto as posições na família como na organização social mais ampla. Mais recentemente, os trabalhos abrangem também outra dimensão, mais diretamente sociológica e política, destacando-se as relações entre as gerações, em um reconhecimento de que se trata de relações de poder - tanto no âmbito da família como no cenário macrossocial das solidariedades e conflitos entre gerações, sobretudo direcionadas para as questões das políticas sociais, com ênfase na proteção social e no discutível debate sobre equidade entre as gerações. Aí um ponto de encontro ou fusão possível com a segunda direção teórica, esta orientada pela tradição sociológica, que vem de Comte a Mentré (1920), e que assume o seu maior amadurecimento e completude com Mannheim (1928).

Mannheim (1964 [1928]) define geração em vários momentos e etapas de desenvolvimento de seu texto $O$ problema das gerações, sempre acentuando seu sentido histórico, "através do pertencimento a uma geração, a um mesmo 'ano de nascimento', se está vinculado de forma parecida à corrente histórica do acontecer social" (idem: 527, tradução nossa), o que significa uma predisposição para "uma modalidade específica do viver e do pensar, uma modalidade específica de intervenção no processo histórico" (ibidem: 528). O autor não desvincula gerações e grupos de idade, destacando que "a conexão geracional [...] não é outra coisa senão uma modalidade específica da mesma posição dada pela proximidade do ano de nascimento no âmbito histórico-social" (ibidem: 529).

Com relação à posição geracional no meio social, Mannheim destaca que ela não se constitui a partir do fato de alguém haver nascido, se tornado jovem, adulto ou velho no mesmo tempo cronológico, mas, da possibilidade - dada a partir desse fato concreto - de "participar dos mesmos acontecimentos, dos mesmos conteúdos de vida etc., e, sobretudo, de fazê-lo a partir do mesmo padrão de estratificação de consciência" (ibidem: 536). Em outras palavras, a posição geracional pode ser defini- 
da como uma espécie de "força social" (cf. Corsten, 2010: 141) que se constitui a partir da vivência de acontecimentos biográficos paralelos que leva indivíduos pertencentes a grupos de idade próximos a desenvolverem perspectivas similares sobre determinados acontecimentos históricos.

No entanto, a simples presença em um momento histórico-social não é suficiente para o desenvolvimento de uma perspectiva ou visão de mundo comum entre indivíduos de idades próximas. Segundo Mannheim, é preciso existir uma conexão geracional entre os mesmos (ibidem: 542-543), ou seja, um tipo de participação em uma prática coletiva, seja ela concreta ou virtual, que produz um vínculo geracional a partir da vivência e da reflexão coletiva em torno dos mesmos acontecimentos. $O$ autor chama ainda a atenção para o fato de que em uma mesma conexão geracional existem distintas unidades geracionais que correspondem a diferentes perspectivas ou posições em relação a um mesmo acontecimento:

A mesma juventude que está orientada pela mesma problemática histórico-atual vive em uma "conexão geracional"; aqueles grupos que dentro dessa mesma conexão geracional processam essas experiências de forma distinta constituem distintas "unidades geracionais" no âmbito da mesma conexão geracional (ibidem: 544 , tradução nossa).

Mas o que estabelece uma relação entre aqueles que partilham de uma mesma unidade geracional não são os conteúdos em si, mas as tendências formadoras de um coletivo surgidas a partir da apropriação desses conteúdos. Nesse sentido, o conceito de gerações rompe com a idéia de unidades geracionais concretas e coesas e nos instiga a centrar nossas análises nas intenções primárias documentadas nos conteúdos, ações e expressões de determinados grupos, ao invés de buscarmos caracterizar suas especificidades enquanto grupo.

Perguntar-se pelos motivos das ações desses atores coletivos envolvidos em processos de constituição de gerações implica uma análise da conjuntura histórica, política e social em que se encontram inseridos. Nesse sentido, a abordagem das relações sociais a partir das posições geracionais significa uma análise inescapável de trajetórias sociais no tempo; no tempo existencial dos indivíduos e no tempo social, coletivo e histórico, portanto, tanto de tendências à mudança como a permanências. 
Os artigos deste dossiê trazem uma reflexão sobre a atualidade do conceito de gerações na pesquisa sociológica, enfocando aspectos relativos às teorias sobre gerações assim como pesquisas sobre as posições geracionais dos sujeitos, com ênfase nas pesquisas sobre a família, o envelhecimento e a juventude.

Carles Feixa e Carmen Leccardi realizam uma reconstrução do conceito de geração na sociologia, iniciando com uma apresentação da visão positivista de Augusto Comte sobre a abordagem histórica de Wilhelm Dilthey e da formulação do conceito por Karl Mannheim. Em seguida, apresentam as contribuições de Philip Abrams para a ampliação da perspectiva mannheimiana do conceito relacionando-o com o conceito de identidade que, na perspectiva do autor, deve ser entendida como resultante do entrelaçamento das histórias individual e social. Na perspectiva de Abrams,

gerações é o lugar em que dois tempos diferentes, o do curso da vida e o da experiência histórica, são sincronizados. O tempo biográfico e o tempo histórico fundem-se e transformam-se criando, desse modo, uma geração social.

Na parte final do artigo, os autores apresentam um breve panorama sobre a utilização do conceito de geração na Itália e na Espanha. No que diz respeito ao debate no contexto italiano, a concepção genealógica de geração definida em termos de descendência vem ganhando terreno e, no âmbito dessas pesquisas, o conceito de "consciência geracional" constitui importante ferramenta de análise. Essa importância se dá pelo fato de o conceito permitir, por um lado, uma interligação entre o tempo biográfico e o tempo geracional e, por outro, uma abertura para a dimensão da reflexividade na análise da dinâmica geracional e dos processos de mudança social.

Outros componentes que remetem para a importância do conceito estão relacionados à historicidade e à estreita relação com a dimensão da experiência, ou seja, com a "capacidade da consciência geracional de promover um contato profundo com o tempo da vida." Nesse sentido, a genealogia passa a ser um importante aliado do conceito de consciência geracional, porquanto o tempo vivido por gerações passadas e reunido em forma de histórias, memórias e experiências conecta a geração seguinte com o tempo histórico e social: "A dimensão genealógica implica por sua vez na consciência de que as mudanças biográficas têm seu próprio lugar determinado pela descendência." 
Em relação ao debate sobre gerações na Espanha, os autores recuperam importantes contribuições do filósofo Ortega e Gasset e de Julián Marias e José Luis López Aranguren. Ambos exerceram influencia decisiva nas concepções de geração e juventude no contexto espanhol, até os anos 1960, quando a teoria das gerações foi posta de lado por ser considerada excessivamente conservadora e antiquada. Foi então substituída por teorias neomarxistas. No entanto, atualmente, os filósofos acima citados estão sendo revisitados por jovens pesquisadores espanhóis da área de juventude e o conceito de gerações volta a ganhar relevância, mesmo sem contribuições maiores para uma "atualização de suas bases teóricas e metodológicas."

Wivian Weller retoma $O$ problema das gerações de Mannheim - que até hoje não chegou a ser integralmente traduzido e publicado no Brasil - destacando os principais aspectos abordados sobre o tema durante a República de Weimer na Alemanha. Apesar de se tratar de um de seus trabalhos mais conhecidos (o conceito de gerações de Mannheim representa, para muitos pesquisadores, a mais completa explicação do tema), o mesmo tem sido muitas vezes citado tão-só por se tratar de um "clássico". A autora chama a atenção para o recorte realizado por alguns cientistas sociais que se apropriam apenas de parte do artigo - sobretudo concernente à geração, conexão geracional e unidade geracional -, destacando que essa divisão conceitual só faz sentido se analisada em seu conjunto, a partir das leituras que levaram Mannheim a essa "conceituação fina" (Forquin, 2003) do conceito de gerações.

Weller buscou assim apresentar uma análise do artigo em sua íntegra, reavivando a relevância do conceito mannheimiano para as pesquisas sociológicas sobre gerações e suas interfaces com outros campos. Conclui destacando:

A atualidade da análise mannheimiana das gerações, reside, por um lado, na elaboração de uma perspectiva multidimensional de análise das relações sociais e geracionais. Por outro, Mannheim nos convida a repensar a construção de instrumentos analíticos capazes de mapear e dar forma à singularidade de experiências concretas, que carecem de uma análise teórica. Em outras palavras, sua perspectiva não representa apenas uma contribuição teórica para os estudos sobre gerações, mas também uma proposta teórico-metodológica de pesquisa, capaz de superar as dimensões binárias presentes em algumas correntes teórico-metodológicas. 
Alda Motta preocupa-se com a escassez relativa do uso do conceito de gerações na análise científica e os sentidos diferenciados que assume nessa análise, atingindo uma polissemia que transborda para o cotidiano e passa a designar até etapas ou modelos do desenvolvimento tecnológico.

Ao mesmo tempo repassa os principais usos do conceito nas ciências sociais e sua possível intercambialidade, deixando implícito o quanto se pode ser, a um só tempo, gerações sociais e posições geracionais na família. Comenta a autora a predominância, no enfoque geracional, do interesse nos segmentos jovens da sociedade, com sua referência implícita ao novo e ao futuro, e a escassa atenção teórica e política dada aos velhos. E não apenas nos estudos e pesquisas do ponto de vista das gerações, mas também em outros âmbitos teóricos, até mesmo no das relações de gênero, em enfoque feminista, no qual - surpreendentemente em um campo de conhecimento onde a dinâmica teórica tem sido acelerada pela intenção política - a condição etária ou geracional é quase invariavelmente omitida.

A autora exemplifica essa falta com a urgente temática da violência. Característica antiga, só agora reconhecida, das resoluções de conflito na sociedade brasileira. Seu atual aparente incremento mobiliza reações em múltiplas frentes, apoiado mesmo por políticas públicas respaldadas em ampla teorização. Entre estas lutas, destaca-se, por sua intensidade e persistência, o movimento feminista, contra a violência sobre a mulher. Mas as muIheres têm diferentes idades, situações geracionais e trajetórias cotidianas que ensejam a deflagração de diferentes tipos de violência. Por isso, ao se analisar a violência contra as mulheres apenas como violência de gênero como é feito no mais das vezes - deixa-se intocado o amplo nicho teórico da violência entre as gerações e, nele, a que se realiza contra os idosos, cometida sobretudo no âmbito doméstico, por filhos e filhas. Consequência que é das relações de poder existentes entre as gerações apenas se observada também a partir dessa perspectiva, poderá ser devidamente elucidada e contida.

Parry Scott apresenta uma visão histórica metodologicamente engenhosa, não do que seria a habitual definição e os usos do conceito de geração em determinado período histórico, mas do lugar social e teórico que as gerações e famílias têm ocupado nas diversas maneiras e possibilidades teóricas de fazer ciência, que sempre foi, também, política, ao longo dos dois últimos séculos. 
Através de uma seleção de autores e de temáticas representativas de diferentes momentos históricos e tendências científicas, acompanha-se as perspectivas de gerações e de família. Estão sempre referidas a situações mais amplas, de mobilidade e de migração internacional.

Acentuada a polissemia que caracteriza o conceito e a prática de realização de gerações e de família, nas ciências sociais, descortina-se um tempo histórico delineado em quatro etapas, a partir do final do século XIX, no qual, em uma primeira fase, a articulação entre famílias e gerações reforçou sobretudo, nas palavras do autor, "a percepção de uma ordem idealizada e a-histórica de evolução e hierarquização". Em seguida, em um segundo momento (primeira metade do século XX), "a história se fazendo mais presente nas interpretações", propiciou lugar para uma diversidade de idéias sobre gerações e sua relação com famílias, soerguendo a família nuclear ou conjugal a uma posição central na construção de esquemas interpretativos".

Ao se valorizar a pesquisa empírica, chega-se às pessoas, aos grupos domésticos e às gerações. Entre várias vertentes de construção do discurso sobre a relação entre gerações e família, naquele momento, sociólogos interessam-se em caracterizar as famílias e as gerações da sociedade ocidental a eles contemporânea: "A referência é mais a crianças, jovens, adultos e idosos (categorias etárias), do que a filhos, pais, avós e netos (categorias relacionais [na família])". É um momento definidor, em que "a maneira diferente pela qual o mundo é vivido por pessoas de diferentes gerações ganha visibilidade", acentua Scott. Mas é um mundo que se urbaniza e moderniza e em que o repetidamente comentado "esgotamento do modelo de desenvolvimento" vai dar lugar a várias formas de críticas e reações às desigualdades, que começam a aparecer não apenas entre as classes sociais mas também entre as gerações e no âmbito das relações de gênero.

A eclosão do feminismo e de movimentos juvenis de contestação são decisivos para a incorporação dessas críticas nas pesquisas acadêmicas:

O grupo doméstico e a família são dissecados por autores de diversas perspectivas, mostrando exploração de mulheres por homens e de gerações mais novas por gerações mais velhas.

Há estudos de jovens, de idosos, de famílias (não mais da família). Numa ampliação do discurso de multiculturalidade, acentua-se o direito à diversidade: 
Valorizam-se fronteiras móveis onde se destaca a pessoa, cujo pertencimento ao grupo Ihe dá direito a uma maneira própria de ser definida em políticas de Estado, reforçado por movimentos e acordos internacionais.

Segundo o autor,

a família não some na compreensão do cotidiano da geração, mas não é o foco privilegiado de ênfase [enquanto] as gerações se apresentam como grupos demandantes de atenção independente no mundo global.

Maria Francisca Pinheiro Coelho e Vitor Leal Santana partem dos conceitos mannheimianos não apenas de gerações, mas também de ideologia e utopia, para examinar dois momentos da trajetória política de uma unidade de geração (ainda conforme Mannheim): 1. o tempo social da juventude, como universitários na década que produziu os anos 1968 mundo afora; e 2. a maturidade etária e política possível em parlamentares nos anos 2000, no Brasil pós-redemocratização. Em ambos os momentos históricos prevalecem, evidentemente, as condições sociais, que ora ensejam ora coíbem as manifestações de ordem geracional.

Contudo, no caso relativo aos anos 1960, em que o foco de análise é a juventude, até certo ponto prevalecem, na ação, a sua condição paradigmática de "olhar para o futuro" e de maior desprendimento do status quo (o que o próprio Mannheim certamente reconheceria como parte do uso que a sociedade faz de suas potencialidades). Entretanto, nos anos 2000, já não se trata de jovens nem de estímulos políticos radicais, mas de outras idades e tempos sociais, com novos interesses e valores. Por isso, após a análise do seu comportamento parlamentar através do conteúdo de projetos de lei e emendas orçamentárias apresentadas em uma legislatura, arrematam Coelho e Santana:

Mesmo que alguns membros daquela geração tentem ver aprovados projetos com o conteúdo ideológico de outrora, se deparam com um sistema político predominante conservador, dificultando modificações no status quo (Figueiredo \& Limongi, 1999). É nesse cenário que devemos avaliar os resultados.

Breitner Tavares se propõe a analisar a configuração de unidades geracionais que se constituíram no contexto de uma cultura juvenil de expansão global, 
mas, ao mesmo tempo, local, na medida em que é ressignificada por aqueles que pertencem ao universo da cultura hip-hop no âmbito do Distrito Federal, especialmente nas regiões administrativas distantes do Plano Piloto. O autor apresenta um breve histórico sobre o hip-hop no Distrito Federal e analisa a imagem desse movimento vinculada pela mídia nos anos 1980 até meados dos anos 1990. Na mídia impressa "a juventude envolvida no hip-hop, especialmente em grupos de break, era criminalizada a partir da perspectiva das gangues e tribos urbanas". No entanto, tal como ocorreu em São Paulo (cf. Weller, 2010, pp. 183-184), "os programas de rádio se tornaram um veículo representativo das atividades relacionadas ao lazer da juventude" na medida em que tocavam novos ritmos como o funk e o rap, divulgavam eventos relacionados ao hip-hop e "promoviam concursos de gravações de mixagens que eram produzidas por pequenas equipes de sonorização espalhadas pelas cidades e responsáveis por pequenas festas locais".

Em um período em que ainda não existia telefone celular e Internet, as rádios comunitárias exerciam um importante papel de comunicação e de divulgação da produção artística desses jovens, de mediação no processo de constituição de uma orientação geracional ou mesmo de uma consciência geracional (cf. Feixa e Leccardi, 2010). Já a partir do final dos anos 1990, "com a popularização de novas tecnologias informacionais que substituíram os antigos discos de vinil pelo CD" a produção e difusão de novos grupos de rap tomou uma nova dimensão.

Atualmente, Tavares observa que vários grupos produzem seus próprios trabalhos e constroem suas redes de distribuição, dentre outras em comunidades virtuais como Orkut ou My Space. Diante dessas configurações que permeiam as novas gerações, é importante a realização de novos estudos voltados para a interpretação e a explicação teórica dos sentidos e significados dessas práticas comuns a esses jovens.

Cabe refletir sobre o real conteúdo das experiências juvenis, sobre o que elas informam, sem violar seu caráter individual ou coletivo, suas especificidades de gênero, de geração, de pertencimento étnico/racial, seus lugares ou não lugares em meio a um universo que torna cada vez mais difícil definir o que é real e o que é virtual, o que caracteriza um estilo ou modo de vida local e o que passou a ser incorporado a partir de outras interseções. 


\section{Referências}

CoRsten, Michael. Karl Mannheims Kultursoziologie. Eine Einführung, Frankfurt/Nova York, Campus, 2010.

FeIXA, Carles \& LeCCARDI, Carmen. "O conceito de geração nas teorias sobre juventude", Sociedade \& Estado, Brasília, Vol. 25 n. 2, mai-ago 2010.

Mannheim, Karl. "Das Problem der Generationen", in idem, Wissenssoziologie [introdução e organização: Kurt H. Wolff], Neuwied, Luchterhand, 1964, pp. 509-565.

—. "El problema de las generaciones" [tradução: Ignacio Sánchez de la Yncera], REIS - Revista Española de Investigaciones Sociológicas, n. 62, abrjun 1993, pp. 193-242.

- "A Educação como trabalho de base", In idem, Liberdade, poder e planificação democrática, São Paulo, Mestre Jou, 1972, pp. 317-339.

Weller, Wivian. Minha voz é tudo o que eu tenho - Manifestações juvenis em Berlim e São Paulo, Belo Horizonte, Editora UFMG, 2010. 